\title{
Treatment of Patent Ductus Arteriosus after Exogenous Surfactant in Baboons with Hyaline Membrane Disease
}

\author{
SENJI SHIMADA,' TONSE N. K. RAJU, RAMA BHAT, HARUO MAETA, AND \\ DHARMAPURI VIDYASAGAR \\ Division of Neonatology, Department of Pediatrics, University of Illinois College of Medicine at Chicago. \\ Chicago, Illinois 60612
}

\begin{abstract}
The effect of early treatment of patent ductus arteriosus (PDA) on the acute course of hyaline membrane disease was tested in a primate model, after intratracheal administration of $100 \mathrm{mg} / \mathrm{kg}$ exogenous bovine surfactant phospholipids at mean ages between $2.3-2.4 \mathrm{~h}$. Twentytwo premature baboons were divided into four groups: seven animals were controls (group $A$ ); five were treated with surfactant but PDA was not intervened (group B); in five surfactant treatment was followed by three doses of $0.2 \mathrm{mg} / \mathrm{kg}$ intravenous indomethacin beginning at a mean age of $5.5 \mathrm{~h}$ (group $\mathrm{C}$ ); and in five surfactant treatment was followed by a surgical ligation of PDA between 5-5.5 h of age. After surfactant instillation in groups $B, C$, and $D, a$ prompt and sustained improvement was noted in $\mathbf{a} / \mathbf{A P O}_{3}$, mean airway pressure, ventilator efficiency index and pulmonary compliance. However, no consistent differences were found in the respiratory variables within the surfacfant treated groups during the 72-h experiment: the respiratory course in the animals treated for PDA (groups $\mathrm{C}$ and $D$ ) was generally similar to the animals in which PDA was not treated (group B). In animals treated with surfactant and indomethacin (group C) the mean aortic blood pressure was maintained more optimally as compared to the other three groups. These findings suggest that although a significant early ductal shunting does occur after exogenous surfactant therapy in this animal model, the expected pulmonary deterioration does not occur, and an early abrupt interruption of PDA does not seem to provide additional advantage to the immediate course of hyaline membrane disease. (Pediatr Res 26:565-569, 1989)
\end{abstract}

\section{Abbreviations}

PDA, patent ductus arteriosus

HMD, hyaline membrane disease

PEEP, positive end-expiratory pressure

PIP, peak inspirator pressure

$\mathrm{FIO}_{2}$, fraction of oxygen in the inspired gas

$P_{A w}$, mean airway pressure

VEI, ventilator efficency index

$L V$, left ventricle

BP, blood pressure

$\mathrm{I} / \mathbf{E}$, inspiratory/expiratory time ratio

Received March 13, 1989; accepted August 21, 1989.

Correspondence T. N. K. Raju, Department of Pediatrics $(\mathrm{m} / \mathrm{c} 856), 840 \mathrm{~S}$ Wood Street, Chicago, IL.

Supported in part by the American Thoracic Society Grant 1985-87 TNKR and the Xavier Ramirez Foundation, University of Illinois at Chicago.

- Presem address Department of Pediatrics, Iwate Medical University, 1-19 Uchimura, Morioka, Iwate, Japan.
Persistence of PDA causing large left-to-right shunting is a well known complication in infants with HMD, particularly during its recovery phase (1). Some studies using exogenous surfactant therapy for the "rescue" of HMD have reported an increased incidence of ductal shunting, perhaps due to a rapid decrease in pulmonary vascular resistance and improvement in pulmonary function after surfactant therapy (2-6). However, other surfactant trials have failed to document an increased PDA incidence (7-9).

The purpose of this study was to evaluate the effect of an early treatment of PDA on the course of HMD after administration of exogenous surfactant. Baboons delivered at $75 \%$ gestation were used in this study. We have previously shown that at this gestation, the premature baboon develops both clinical and pathologic features of typical HMD, and manifests left-to-right ductal shunting (5).

\section{MATERIALS AND METHODS}

Animal preparation. The study protocol was approved by the Animal Care Committee of the University of Illinois at Chicago. Using $5-10 \mathrm{mg} / \mathrm{kg}$ ketamine as premedication, and $50 \%$ nitrous oxide with $0.5 \%$ halothane as anesthesia, cesarean section was performed on date-mated Papio anubis species baboons at 139 $141 \mathrm{~d}$ pregnancy (term $180 \mathrm{~d}$ ). The newborn baboon was dried, and placed on a heating pad under a radiant lamp. Ainway was suctioned, and bag and mask ventilation was provided using $100 \% \mathrm{O}_{2}$ during the first $3-5 \mathrm{~min}$ that is required for tracheotomy (under local anesthesia). A $2.5 \mathrm{-mm}$ internal diameter endotracheal tube was secured as airway. The chest was squeezed and lung fluid suctioned. Mechanical ventilation was then begun using a pressure limited time-cycle ventilator (Baby-Bird, Bird Corporation, Palm Springs, CA) with the following settings: $\mathrm{FiO}_{2}$ 1.0; peak inspiratory pressure $30 \mathrm{~cm} \mathrm{H}_{2} \mathrm{O} ;$ PEEP $4 \mathrm{~cm} \mathrm{H} \mathrm{H}_{2} \mathrm{O}$; rate $40 / \mathrm{min}$; and $\mathrm{I} / \mathrm{E}$ ratio $1: 1$.

A central venous catheter was inserted via the right jugular vein for blood transfusion, and for fluid and drug administration. Catheters were also placed in the descending aorta for measuring BP and for obtaining blood samples, and into the left ventricle via the right common carotid artery for microsphere studies. After the third microsphere injection, the left ventricle catheter was pulled back to the level of the ascending aorta. Catheter positions were ascertained from pressure tracings, chest-abdominal $x$-rays, and confirmed at autopsy. After catheterization, the baboon was placed in a specially designed incubator for subsequent care.

Experimental protocol. Animals had been assigned to one of four treatment groups before delivery: group $A$, no surfactant treatment and no PDA intervention; group $B$, surfactant treatment and no PDA intervention; group $C$, surfactant treatment 
followed by pharmacologic treatment of PDA; group D, surfactant treatment followed by surgical ligation of PDA.

In groups B, C, and D $100 \mathrm{mg} / \mathrm{kg}$ saline sonicated suspension of exogenous bovine surfactant phospholipids (surfactant TA), was used within $15 \mathrm{~min}$ after the first microsphere injection at 2 $h$ of age (2-5). Using a no. $3.5 \mathrm{~F}$ catheter, about one-fourth the total surfactant dose was instilled into each lung quadrant, while tilting the chest into appropriate positions in sequence (5). Hand ventilation was provided for $30 \mathrm{~s}$ between aliquots instilled, using $100 \%$ oxygen, $30-35 \mathrm{~cm} \mathrm{H}_{2} \mathrm{O}$ PIP, and $40-60 / \mathrm{min}$ rate; mechanical ventilation was resumed subsequent to surfactant dosing. In group $\mathrm{A}, 3 \mathrm{~mL} / \mathrm{kg}$ of air was injected into the trachea using similar technique.

In group $\mathrm{C}$ animals, $0.2 \mathrm{mg} / \mathrm{kg}$ indomethacin was given intravenously at $5.5 \mathrm{~h}$ of age, within $15 \mathrm{~min}$ after the second microsphere study. This dose was repeated at 18 and $30 \mathrm{~h}$ of age. In group D, the ductus was surgically ligated via a posterolateral, transpleural approach under local anesthesia (Lidocaine $0.1 \%$ ) at $5.5 \mathrm{~h}$ of age, also within $15 \mathrm{~min}$ after second microsphere study. During surgery the $\mathrm{FiO}_{2}$ was kept at 1.0 , and care was taken to maintain body temperature at $37.5 \pm 0.5^{\circ} \mathrm{C}$. Before closure of thoracotomy, a $3.0-\mathrm{mm}$ tube was placed in the lower pleural space, and connected to an under-water seal drainage to detect pneumothorax.

Measurements and calculations. The lung fraction of LV output was measured by microsphere technique (15) at 2,5 , and 10 $h$ of age. Fifteen $\mu$ diameter microspheres labeled with ${ }^{51} \mathrm{Cr}$, ${ }^{141} \mathrm{Ce}$, and ${ }^{85} \mathrm{Sr}$ (New England Nuclear Laboratories, Boston, MA), suspended in $1 \mathrm{~mL} 10 \%$ glucose were injected into the left ventricle over $15-20 \mathrm{~s}$. The catheter was flushed with $1 \mathrm{~mL}$ normal saline. The injection apparatus was counted and subtracted from preinjection counts to determine the total counts injected. Percentage of LV output diverted to the lungs was calculated by dividing the total counts in the lung (removed at autopsy), by the total counts injected into the left ventricle (12). Counts from all samples of each study were determined simultaneously.

To visualize the PDA, a single-shot aortography was performed at $72 \mathrm{~h}$ of age just before the planned termination of the experiment (5). Animals were then ventilated with $100 \%$ oxygen for 15 min to degass the lung, after which they were killed with a lethal dose of phenobarbital. Pressure volume characteristics of the lung were examined as described before (5).

Arterial BP (from the aortic catheter) was measured with a pressure transducer (Bently Trantec, Irvine, CA) and recorded on a multichannel recorder (Gould Inc., Cleveland, $\mathrm{OH}$ ). Respiratory settings including PIP, PEEP, and $\mathrm{P}_{\mathrm{AW}}$ were monitored using a proximal airway pressure monitor (Pneumogard 1230A, Novametrix Inc., Wallingford, CT). Tidal volume was measured sequentially with Fleish pneumotachometer (no. 000), a differential pressure transducer (Validyne Engineering Corporation, Northridge, CA) and carrier amplifier (Gould). Lung-thorax compliance was calculated by dividing tidal volume $(\mathrm{mL} / \mathrm{kg}$ body wt) by the $\Delta$ PIP-PEEP as measured at the proximal airway (11, 12). Arterial to alveolar oxygen tension ratio (a/APO2) was computed after calculating alveolar oxygen tension (I3), assuming 0.8 for respiratory change ratio. VEI, an analogue of dynamic compliance, was calculated (14).

Animal care. ECG, BP, heart rate, and recta' temperature (maintained at $37.5 \pm 0.5^{\circ} \mathrm{C}$ ) were continuously monitored. Pancuronium bromide ( $100 \mu \mathrm{g} / \mathrm{kg}$ intravenously) was used for paralysis, and mechanical ventilation was provided throughout the study. The respirator settings were adjusted to maintain $\mathrm{PaO}_{2}$ between $50-100 \mathrm{~mm} \mathrm{Hg}$, and $\mathrm{PaCO}_{2}$ between $30-45 \mathrm{~mm} \mathrm{Hg}$. PIP and frequency were adjusted to normalize $\mathrm{PaCO}_{2}$ : when the rate requirement was $\geq 40 / \mathrm{min}$, the $I / E$ ratio was fixed at $1: 1$, and at rates $\leq 40 / \mathrm{min}$, inspiratory time was held between $700-$ $750 \mathrm{~ms}$. Maximum PIP was limited to $45 \mathrm{~cm} \mathrm{H} \mathrm{H}_{2} \mathrm{O}$, because of risk of pneumothorax. $\mathrm{FiO}_{2}$ and $\mathrm{PEEP}$ were adjusted to normalize $\mathrm{PaO}_{2}$ : when $\mathrm{PaO}_{2}$ was $<50 \mathrm{~mm} \mathrm{Hg}$ in $100 \%$ oxygen, PEEP was increased to $6 \mathrm{~cm} \mathrm{H}_{2} \mathrm{O}$, which was decreased to $3 \mathrm{~cm} \mathrm{H}_{2} \mathrm{O}$ when oxygen requirement fell to $<35 \%$. Sodium bicarbonate ( $1-$ $2 \mathrm{mEq} / \mathrm{kg}$ ) was used to correct metabolic acidosis.

A $10 \%$ solution of dextrose was used as maintenance fluid at $80 \mathrm{~mL} / \mathrm{kg}$ on the first day, $100 \sim 120 \mathrm{~mL} / \mathrm{kg}$ thereafter. Heparinized saline $(1 \mathrm{U} / \mathrm{mL})$ was infused through the arterial catheters at $0.3-0.5 \mathrm{~mL} / \mathrm{kg} / \mathrm{min}$ to prevent clotting. Circulatory failure (mean aortic BP $<25 \mathrm{~mm} \mathrm{Hg}$, without hypoglycemia, hypocalcemia, or hypovolemia), was treated with infusion of dopamine at $5 \mu \mathrm{g} / \mathrm{kg} / \mathrm{min}$ starting dose, and increased up to $30 \mu \mathrm{g} / \mathrm{kg} / \mathrm{min}$ as required.

Data analyses. One-way analysis of variance and NeumanKeuls multiple comparison procedures were used to test the difference in mean values among the groups, and for pair-wise comparisons, respectively (16). Differences in the mean \% LV output to the lungs were tested using Kruskal-Wallis test. $\chi^{2}$ with Yate's correction, and paired $t$ tests were used when appropriate. A $p$ value $<0.05$ was considered statistically significant.

\section{RESULTS}

Twenty-two infant baboons with typical features of severe HMD (5) were studied. Birth weight, gestational age, sex distribution, age at treatment with surfactant or air, and age at PDA intervention did not differ significantly among the four groups of animals (Table 1). The first blood gas/acid base studies performed within $30 \mathrm{~min}$ of age showed no evidence of acidosis, hypoxia, or hypercapnea in any of the four groups: the mean $\mathrm{pH}$ value ranged between 7.34-7.38, $\mathrm{PaO}_{2}$ between $120.0-194 \mathrm{~mm}$ $\mathrm{Hg}$, and $\mathrm{PCO}_{2}$ between $28.6-36.6 \mathrm{~mm} \mathrm{Hg}$. These values were not significantly different among the groups. Approximately $20-30$ min were required to ligate the PDA (in group D). The external diameter of the ductus was noted to be equal to that of the descending aorta in all group $\mathrm{D}$ animals.

Four baboons in group A developed pneumothorax between $25-35 \mathrm{~h}$ of age, and died between $26-69 \mathrm{~h}$ of age. None in the three surfactant groups developed pneumothorax. One animal each from groups B, C, and D died of circulatory failure between 24-55 h of age. The cardiopulmonary condition of the remaining 15 animals was completely stable until study termination as was reflected in the vital signs, metabolic acidosis, blood pressure, urine output, and skin perfusion.

Mean urine output remained less than $1 \mathrm{~mL} / \mathrm{kg} / \mathrm{h}$ during the first $36 \mathrm{~h}$ of age in all four groups: the values ranged between $0.7-0.8 \mathrm{~mL} / \mathrm{kg} / \mathrm{h}$, suggesting significant oliguria. In group $\mathrm{C}$ urine output returned to normal of $2.7 \mathrm{~mL} / \mathrm{kg} / \mathrm{h}$ by $36 \mathrm{~h}$, and ranged between $3.2-3.6 \mathrm{~mL} / \mathrm{kg} / \mathrm{h}$ during the remainder of the study. By contrast, in groups A, B, and D urine output returned to the normal values of $1.7-2.0 \mathrm{~mL} / \mathrm{kg} / \mathrm{h}$ at $48 \mathrm{~h}$ of ageapproximately $12 \mathrm{~h}$ later than in group $\mathrm{C}$. Urine output ranged between $1.8-3.1 \mathrm{~mL} / \mathrm{kg} / \mathrm{h}$ between $48-72 \mathrm{~h}$ of age. Except for approximately $12 \mathrm{~h}$ early onset of normalization of urine output in group $\mathrm{C}$, the changes in urine output did not differ significantly among the four groups of animals.

Arterial blood gases and pulmonary variables. There were no statistically significant differences in $\mathrm{PaO}_{2}$ between the groups during the study period. In group $\mathrm{A}, \mathrm{PaCO}_{2}$ was significantly ligher between $10-30 \mathrm{~h}$, and arterial $\mathrm{pH}$ was significantly lower at $10 \mathrm{~h}$ as compared to groups $\mathrm{B}, \mathrm{C}$, and D. Before surfactant instillation, no significant differences were seen in $\mathrm{a} / \mathrm{APO}_{2}, \mathrm{P}_{\mathrm{AW}}$ compliance, and VEI among the groups (Fig. 1). Because of a prompt improvement in a/ $\mathrm{APO}_{2}$ after surfactant treatment, we could reduce $P_{A w}$ in groups $\mathrm{B}, \mathrm{C}$, and $\mathrm{D}$, whereas in group $\mathrm{A}$, $\mathrm{P}_{\mathrm{AW}}$ requirements remained significantly higher (Fig. $1 A$ and C).

Although respiratory variables were generally similar among the surfactant treated groups, in group $\mathrm{D}$, mean a/APO $\mathrm{Aalues}_{2}$ tended to be lower, particularly after PDA ligation, as compared to $\mathrm{B}$ and $\mathrm{C}$ (Fig. $\mathrm{I} A$ ); the differences were statistically significant at $16 \mathrm{~h}$ (compared to $\mathrm{B}$ ) and at $48 \mathrm{~h}$ (compared to C). No 